\title{
Homofobia no futebol masculino: revisão narrativa de literatura
}

\author{
Homophobia in male soccer: \\ narrative literature review
}

\section{Daniel Cerdeira de Souza}

Universidade Federal de Santa Catarina (Florianópolis). Santa Catarina, Brasil. dancerdeira01@gmail.com

RESUMO | INTRODUÇÃO: O Brasil é conhecido como o país do futebol, que é um campo de encontro de masculinidades regidas pela norma heterossexual, onde dissidentes desse aspecto podem ser marginalizados nesse espaço. OBJETIVO: Dessa forma, este estudo objetivou discutir a homofobia no contexto do futebol. MÉTODOS: Metodologicamente, esta é uma revisão narrativa da literatura, onde foram analisados 6 artigos, 5 em português e 1 em inglês, publicados entre 20122018 indexados nas bases de dados Scielo, PEPSIC, BVS e Capes. Os dados coletados foram analisados a partir da elaboração de um protocolo de revisão e posteriormente a partir da técnica Análise de Conteúdo. RESULTADOS: Os resultados foram compilados em cinco categorias: 1) Futebol como contexto de performatividade de masculinidade; 2) Homossexuais no futebol; 3) A homossociabilidade no futebol; 4) Os estádios, a torcida, a linguagem e a mídia; 5) Torcidas queers e inclusão, que discutiram que o futebol é um contexto de performatividade da masculinidade hegemônica do projeto heterossexual, onde homossexuais tem sua participação limitada e/ou banida. CONSIDERAÇõES FINAIS: Caso desejem participar do esporte, homossexuais precisam se adequar a norma heterossexual, geralmente permanecendo no armário. É permitida a homossociabilidade no futebol como forma de amor ao time e a linguagem é usada como meio onde a violência homofóbica é expressada, mas admite-se que mudanças nesse cenário estão ocorrendo, ainda que a passos lentos, possibilitando a proposta de masculinidades inclusivas. Conclui-se que o futebol representa bem mais do que um esporte, mas um jogo político e um dispositivo da sexualidade, que regula as relações de gênero entre homens.

PALAVRAS-CHAVE: Homofobia. Masculinidades. Futebol. Esporte.
ABSTRACT | INTRODUCTION: Brazil is well-known as the country of soccer football, a meeting place for masculinities, guided by the heterosexual norm, where dissidents of this aspect can be marginalized within this space. OBJECTIVE: This study aimed to discuss homophobia in this context. METHODS: Methodologically, this is a narrative literature review; six articles were analyzed, 5 in Portuguese and 1 in English, published between 2012-2018 and indexed in the Scielo, PePsic, BVS, and Capes databases. The collected data were analyzed using a review protocol and later from the Content Analysis technique. RESULTS: The results were compiled in five categories: 1) Soccer as a context of male performance; 2) Homosexuals in football; 3) Homosociality in football; 4) Stadiums, fans, language, and the media; 5) Queer cheerleading and inclusion, which argued that football is a context of performativity for the hegemonic masculinity of the heterosexual project, where homosexuals have their participation limited and/or banned. FINAL CONSIDERATIONS: Homosexuals need to conform to the heterosexual norm if they wish to participate in the sport, usually remaining in the closet. Homosociability in football is allowed as a form of love for the team, and language is used as a way to express homophobic violence, but it is admitted that changes in this scenario are taking place, even if at a slow pace, enabling the proposal of inclusive masculinities. It is concluded that football represents much more than a sport, but a political game and a device of sexuality, which regulates gender relations between men.

Keywords: Homophobia. Masculinities. Soccer. Sport. 


\section{Introdução}

O Brasil é conhecido mundialmente como o país do futebol. Esta imagem só se consolidou após a conquista do primeiro campeonato mundial na Suécia, em 1958. O futebol um campo de produção e reprodução de subjetividades, produção de paz e de violência, porém, nem todas as pessoas possuem livre acesso a esse esporte (Leoncini, 2005; Caldas, 1986). Os esportes não são independentes em relação à sociedade na qual eles se desenvolveram e seus valores são atualizados em conformidade com a estrutura social em que estão inseridos (Abrahao \& Soares, 2012).

O futebol apresenta-se como um contexto de relações de gênero, com especial importância ao futebol masculino. Para Butler (2003), o gênero não deve ser meramente concebido como o significado cultural inscrito num sexo previamente dado, ele também designa o aparato de produção mediante o qual os próprios sexos são estabelecidos. O gênero produz a falsa noção de estabilidade no qual a matriz heterossexual está amparada e essa manutenção se dá pela através da performatividade, ou seja, pela repetição de atos, gestos e signos, do âmbito cultural, que reforçariam a construção dos corpos masculinos e femininos de forma binária como nós os vemos atualmente, dessa forma, para Butler, gênero é a repetição intencional que produz significados. Dessa forma, tanto o sexo quanto o gênero são construídos socialmente.

Dessa forma, o futebol pode ser pensado como um contexto produção e reprodução de masculinidades. Kimmel (1998) ressalta que não podemos mais falar em um único modelo de ser masculino, mas de vários modelos de masculinidades, as quais são construídas simultaneamente em dois campos inter-relacionados de relações de poder: nas relações de homens com mulheres (desigualdade de gênero) e nas relações dos homens com outros homens (desigualdades baseadas em marcadores interseccionais, como raça, etnicidade, sexualidade, idade, etc). Outro ponto importante é que o poder das masculinidades é frequentemente algo invisível aos homens cuja ordem de gênero é mais privilegiada com esse poder em relação àqueles que são privilegiados, ou seja, os processos que conferem o privilégio a um grupo e não a outro grupo são frequentemente invisíveis àqueles que são privilegiados.
Butler (2003) explica que as expressões de masculinidade impõem formas de funcionamento tão intrínsecas na sociedade que não são percebidas e, por consequência, são repetidas, visto que, em nossa sociedade, estamos diante de uma exigência de coerência total entre um sexo, um gênero e um desejo/ prática heterossexual, assim, as masculinidades que mais se adequam a norma heterossexual teriam privilégios sociais não percebidos por quem a performatiza em relação a aqueles que subvertem a norma.

Assim, o futebol no Brasil, como esporte de espetáculo e de contato, exige a performatividade de características conhecidas tipicamente como masculinas, como a virilidade e força (Bandeira, 2010). Dessa forma, pessoas dissidentes desses aspectos podem ser marginalizadas e excluídas desse espaço. Nesse contexto encontram-se, dentre outras, pessoas homossexuais, recorte desse estudo. Rubin (2003) discute que o sistema sexo/gênero serve como um dispositivo para controlar e disciplinar a organização social. Com isso, o mesmo funciona como uma tecnologia que auxilia a subordinação (dentre outros) dos homens homossexuais aos homens heterossexuais., dessa forma, considerando o contexto social das relações de gênero na norma heterossexual e como o futebol pode servir de campo de performatividades, este estudo objetivou analisar a literatura publicada no formato de artigos científicos em português e inglês entre 2012-2018 sobre a homofobia no futebol.

Historicamente estabeleceu-se uma norma para controlar as condutas ditas normais, baseada em relações de poder, em que a referência está pautada no homem heterossexual, branco, cristão, urbano e de classe média. Todos aqueles que não se encaixam neste padrão são denominados "outros" e que serão definidos em contraponto ao modelo. A heteronormatividade que se define por uma norma compulsória à heterossexualidade, está apoiada na ligação entre sexo, gênero e expressão da sexualidade (Louro, 2000).

Sendo definida basicamente como a atração sexual por pessoas do mesmo gênero/sexo, a homossexualidade é carregada de valores morais e construções histórico-culturais. No decorrer da história ocidental, a homossexualidade ora foi aceita, ora foi condenada, ora ignorada ou deliberadamente escondida (Martins, 2015; Menezes \& Brito, 2007). Por subverterem a linearidade sexo/gênero/expressão 
da sexualidade, homossexuais muitas vezes são tidos como pessoas a margem da sociedade, passíveis de correções (tratamentos médicos, psicológicos e afins) que os trariam de volta a heteronorma ou mesmo discriminações que os tornariam corpos matáveis.

O termo homofobia é utilizado para a nomear a violência e discriminação contra indivíduos que apresentem orientação sexual e identidade de gênero diferente dos padrões propostos pela heteronormatividade (Costa \& Nardi, 2015). A homofobia surge como um conceito polissêmico, fenômeno plural e faz referência a um conjunto de emoções e comportamentos negativos de uma pessoa ou grupo em relação aos homossexuais. Ela é um dispositivo de controle que reforça a ideia de naturalização da normalidade relacionada à heterossexualidade e que se manifesta nas relações sociais por meio de agressões de leves a severas, na negação de direitos e também simbolicamente (Natarelli et al, 2015).

Uma pesquisa realizada pela Organização das Nações Unidas para a Educação, Ciência e a Cultura (Unesco) revelou que $25 \%$ dos estudantes pesquisados não gostariam de ter um colega de classe homossexual (resposta majoritariamente emitida por estudantes do sexo masculino) (Castro, Abramovay \& Silva, 2004). Por toda história da humanidade, pessoas $\mathrm{LGBT}^{\prime} \mathrm{s}^{1 *}$ foram colocadas à margem da sociedade. A discriminação contra esse grupo social pode ocorrer de diversas formas e locais. Dados de 2013, apresentam registros de 1.695 denúncias de 3.398 violações relacionadas à população LGBT pelo Disque Direitos Humanos (Disque 100) (Secretaria Especial de Direitos Humanos, 2016).

Homossexuais também são discriminados no contexto esportivo. Camargo (2018) discute que dados os significados sobre a homossexualidade em vigor, atletas que assumem sua essa orientação sexual ficam expostos a violências estruturais, como retaliações não somente na arena da prática esportiva, mas fora dela, como por exemplo nas redes sociais e também ficam sujeitos a perderem contratos publicitários e patrocínios, o que leva muitos homossexuais a nunca falar nada sobre sua orientação sexual nesse contexto, pois assumir sua homossexualidade nesse contexto, de acordo com De Carvalho (et al, 2017) ainda é considerado um escândalo.

Dessa forma, corroborando com De Carvalho (et al, 2017) quando os autores consideram o esporte como um campo masculino e entendendo o futebol como um campo de performatividade de masculinidades da norma heterossexual, a pergunta que norteia esse estudo é: O que a literatura publicada no formato de artigos científicos entre 2012 - 2018 tem discorrido sobre a homofobia no contexto do futebol masculino?

\section{Método}

Como caminho metodológico, escolheu-se a revisão narrativa de literatura, caracterizada a partir de uma temática aberta que não segue necessariamente um protocolo rígido na sua confecção e apresenta as referências do autor, seu lugar de fala e campo de análise (Cordeiro, Oliveira, Rentería, \& Guimarães, 2007).

Os descritores utilizados foram: "Homofobia AND Futebol" devidamente validados nos Descritores da Biblioteca Virtual de Saúde (Decs BVS). Como critérios de inclusão, foram selecionados artigos científicos com configuração temporal entre janeiro de 2012 até junho de 2018 publicados em língua portuguesa e inglesa. Foram excluídas outras fontes de possíveis análises (livros, teses, dissertações e afins).

Com a aplicação dos descritores em língua portuguesa, na base de dados Scielo, foi encontrado 1 resultado. Na BVS, 3 resultados, na Pepsic não foi encontrado nenhum resultado. $\mathrm{Na}$ base Capes, 7 resultados. Com a aplicação dos descritores em língua inglesa, não foram encontrados resultados nas bases Scielo e Pepsic. Na BVS foi encontrado 1 resultado e na Capes foram encontrados 8 resultados. A coleta foi realizada entre os dias 28 e 30 de junho de 2018.

${ }^{1}$ Lésbicas, Gays, Bissexuais, Travestis e Transexuais, sigla padronizada na $1^{\circ}$ Conferência Nacional LGBT no ano de 2008 em Brasília. O sinal gráfico * tem por objetivo tornar a sigla LGBT aberta, pensando nas demais performances dissidentes da norma heterossexual que não são compreendidas pela sigla. 
De maneira geral, os 20 resultados foram coletados foram descritos em uma planilha do Excel para se verificar se todos eram publicações no formato de artigos. Nesse momento, todos os resultados contemplavam esse critério e nenhum foi excluído. $O$ próximo passo foi a exclusão dos artigos repetidos nas bases, onde 5 artigos foram excluídos. Após, foi realizada a leitura completa dos 15 artigos restantes, para exclusão dos que não apontavam para a temática desse estudo, nesse momento, 9 artigos foram excluídos por não estarem dentro do tema delineado. Tivemos como amostra final 6 artigos para análise, sendo 5 em língua portuguesa e 1 em língua inglesa.

Os 6 artigos restantes foram lidos de maneira integral e analisados através da criação de um instrumento para análise descritiva dos artigos. Este instrumento baseia-se nos estudo de Evans e Pearson (2001) e conteve: a pergunta da revisão, os critérios de inclusão e as estratégias de busca, assim descritos: 1) a identificação (título do artigo, título da revista em que foi publicado o artigo, base de dados, ano e autores e país da publicação); 2) metodologia do estudo; 3) as principais considerações/resultados e pergunta da pesquisa e 4) um campo para que se justifique caso o estudo seja excluído da amostra final. Após a análise, o revisor deu seu parecer de "selecionado" ou "não selecionado" para cada artigo, seguindo o critério de relevância do estudo para a amostra e se o mesmo contemplava a temática proposta de forma integral.

Concluído o processo de categorização, teve início a Análise de Conteúdo para analisar os dados extraídos dos artigos. Esse procedimento organiza-se em três fases, segundo Bardin (2011): I) Pré-Análise: É a organização de todos os materiais utilizados da coleta dos dados (correspondente a organização e leitura dos artigos no protocolo). II) Exploração do Material: que consiste nas operações de codificação em função das regras que já foram previamente formuladas (após a leitura no protocolo, criou-se as categorias). III) Tratamento dos resultados: É a fase de análise propriamente dita, onde os resultados brutos serão tratados de maneira a serem significativos (discussão dos dados).

\section{Resultados}

Dos 6 artigos selecionados para análise no protocolo de revisão, um foi publicado em 2012, 4 foram publicados no ano de 2014 e outro em 2017. Um foi publicado nos EUA e 5 no Brasil. Quanto ao tipo de estudo, 4 caracterizaram-se por serem estudos teóricos e 1 foi pesquisa qualitativa e outra pesquisa quantitativa. A seguir, caracterizamos os artigos analisados:

Quadro 1. Caracterização dos artigos analisados

\begin{tabular}{|c|c|c|c|c|}
\hline Base & Título do artigo & Periódico & Método & Autor (es)/Ano \\
\hline Scielo & $\begin{array}{l}\text { Preconceito contra } \\
\text { homossexuais no contexto do } \\
\text { futebol }\end{array}$ & $\begin{array}{l}\text { Psicologia \& } \\
\text { Sociedade }\end{array}$ & Quantitativo & Pereira et al 2014 \\
\hline \multirow{5}{*}{$\begin{array}{l}\text { Periódicos } \\
\text { CAPES }\end{array}$} & $\begin{array}{l}\text { O futebol no banco dos réus: } \\
\text { caso da homofobia. }\end{array}$ & Movimento & Teórico & $\begin{array}{l}\text { Almeida \& Soares, } \\
2012\end{array}$ \\
\hline & $\begin{array}{l}\text { Association Football and the } \\
\text { Representation of Homosexuality } \\
\text { by the Print Media: A Case Study } \\
\text { of Anton Hysén }\end{array}$ & $\begin{array}{l}\text { Journal of } \\
\text { Homosexuality }\end{array}$ & Qualitativo & Cleland, 2014 \\
\hline & $\begin{array}{l}\text { O direito em fala: sobre bichas e } \\
\text { homens no futebol brasileiro }\end{array}$ & $\begin{array}{l}\text { Revista Espaço } \\
\text { Acadêmico }\end{array}$ & Teórico & Moura, 2017 \\
\hline & $\begin{array}{l}\text { Torcidas Queer e Livres em } \\
\text { Campo: Sexualidade e Novas } \\
\text { Práticas Discursivas no Futebol }\end{array}$ & Ponto Urbe & Teórico & Pinto, 2014 \\
\hline & $\begin{array}{l}\text { Da coligay ao sheik - } \\
\text { (re)produção da } \\
\text { homossexualidade no espaço de } \\
\text { masculinidades: uma análise de } \\
\text { discursos no campo futebolístico }\end{array}$ & $\begin{array}{l}\text { Oficina do } \\
\text { Historiador - } \\
\text { EDIPUCRS }\end{array}$ & Teórico & Silva, 2014 \\
\hline
\end{tabular}




\section{Discussão}

Após a análise dos dados extraídos dos seis artigos a partir da análise de conteúdo de Bardin (2011), foram criadas cinco categorias, discutidas e problematizadas a seguir:

\section{Futebol como contexto de performatividade de masculinidade}

Ao longo da história, os esportes de equipe masculina, muitas vezes, forçaram meninos e homens a demonstrarem noções socialmente aceitáveis de masculinidade. O futebol fornece um exemplo histórico disso, onde a incorporação masculina (incluindo força física e poder, bem como a demonstração de heterossexualidade) na identidade e expressão foram naturalizadas (Cleland, 2014). O futebol oferece uma interminável trama de ações para o desenvolvimento da reprodução de masculinidades já existentes no contexto social. O modo de ser homem, a partir da performance no estádio de futebol é a reprodução da masculinidade da sociedade (Moura, 2017). A masculinidade tipicamente encontrada nesse esporte é centrada em torno da heterossexualidade e hipermasculinidade, que resulta na subordinação daqueles que não se conformam a esses valores (Cleland, 2014). O homem tido como viril é reconhecido como participante legítimo e "natural" dos rituais e práticas relacionadas ao futebol (Pinto, 2014). Assim, é sugerido que outras expressões de masculinidades que não sejam a tradicional e viril, comumente conhecida como hegemônica, sejam censuradas (Moura, 2017).

Connell e Messerschmidt (2013), clássicos autores sobre os estudos de masculinidades, discutem que o conceito de masculinidade hegemônica é entendido como um padrão de práticas que possibilita a dominação de homens sobre todo o tecido social. Ela é normativa e incorpora a forma "mais honrada" de ser homem, exigindo que todos os outros homens sejam subordinados a ela. Ela baseia-se em práticas de gênero que são aceitas socialmente, estabelecendo posições de dominantes e dominados e expressa uma posição sempre em disputa (Gomes, 2008).
Já Judith Butlher (2003), bebendo dos estudos pós estruturalistas de Michel Foucault, problematiza o gênero ao dizer que as masculinidades não estão dadas, mas seus conceitos estão dispostos na sociedade e precisam ser sempre imitados e reconfirmados. Dessa forma, observamos que futebol pode funcionar como um campo onde a masculinidade heterossexual viril encontra espaço para ser reforçada como verdade, não deixando espaço para outras expressões de gênero.

A construção social sobre a masculinidade se pressupõe como o delineamento do futebol. Em se tratando de um jogo para além do lazer ou da partida profissional, o espaço do futebol determina práticas específicas dentro do seu contexto, sendo a representação de si mesmo e do que o jogo representa. Logo, a partida de futebol é um momento político específico, espetáculo de desempenho de papéis, de exaltação e subordinação de masculinidades (Moura, 2017, Almeida \& Soares, 2012).

A respeito da hierarquização esportiva há uma diferenciação dos esportes e práticas de lazer: às muIheres estimula-se a ginástica e o ballet, para fins de conformação dos corpos e aos homens incita-se esportes competitivos, para fortalecer o corpo e exercitar o convívio regrado entre iguais (Pereira et al, 2014), sendo que esse jogo de divisão na ocupação dos espaços sociais faz parte do projeto da linearidade entre sexo/gênero/expressão de sexualidade discutida por Louro (2000).

\section{Homossexuais no futebol}

No contexto do futebol a aversão contra homossexuais é fortemente evidenciada, por se tratar de um ambiente de "homens para homens", onde se performatiza a masculinidade hegemônica heteronormativa (Pereira et al., 2014). O estereótipo do homossexual é incongruente aos olhos dos espectadores devido ao rompimento com a norma heterossexual, assim homossexuais no futebol podem não ser inteligíveis aos olhos sociais, pois o futebol é entendido como reduto da força física, como se a liberdade sexual estivesse ligada a ter ou não força, ter ou não virilidade (Almeida \& Soares, 2012). 
Retomando Connell (1995), existem mais três outros padrões principais de masculinidade na ordem de gênero do ocidente: A masculinidade subordinada, que diz respeito à dominância e subordinação entre grupos de homens, como é o caso da dominação dos homens heterossexuais e a subordinação dos homens homossexuais. A masculinidade cúmplice se define pela conexão com o projeto de masculinidade hegemônica, mas sem a completa incorporação deste projeto. São masculinidades cúmplices porque percebem e desfrutam de algumas vantagens do patriarcado sem defenderem publicamente esta posição e a masculinidade marginalizada, que se refere a relações entre as masculinidades e classes ou grupos étnicos dominantes e subordinados; é uma masculinidade que está marginalizada devido à condição subordinada de classe ou raça.

Nesse sentido, homossexuais ficariam subordinados a heterossexuais em todos os contextos do futebol. Parte-se do entendimento que o futebol reproduz às regras rígidas da masculinidade hegemônica. Essa questão é tão forte e disseminada no âmbito esportivo que, aparentemente, imagina-se anulada a possibilidade de coexistência de atletas gays nesse espaço e quando eles ocupam espaço nesse esporte, geralmente escondem sua orientação sexual, pois o futebol permanece como uma das maiores instituições segregadoras de gênero das culturas ocidentais (Almeida \& Soares, 2012).

Dessa forma, o futebol funcionaria como um "dispositivo" da sexualidade, conforme Foucault (1996). O autor explica que o conceito de "dispositivo" corresponde a um conjunto heterogêneo que engloba discursos, instituições, decisões regulamentares, leis, medidas administrativas, enunciados científicos, proposições filosóficas, morais, filantrópicas e etc. que visam normatizar, controlar e estabelecer "verdades" a respeito do corpo e da sexualidade. Assim, pode-se problematizar que a forma de apreender o futebol não é remetida apenas a um esporte, mas o futebol auxilia como um dos pilares organizadores das relações sociais de gênero, um codificador de condutas masculinas (Pereira et al., 2014).

Homossexuais e mulheres heterossexuais são figuras historicamente segregadas de práticas que dão sentido ao futebol, como o jogar e o torcer. Por meio da violência simbólica, mulheres e homens homossexuais veem-se constrangidos e mesmo sem legitimidade para frequentar os estádios na condição de torcedor. A violência simbólica, segundo Bourdieu (1989) está presente nos símbolos e signos culturais, especialmente no reconhecimento tácito da autoridade exercida por certas pessoas e grupos. Deste modo, ela muitas vezes não é percebida como violência, mas sim como uma espécie de interdição desenvolvida com base em um respeito que "naturalmente" se exerce de um para outro. Como exemplo disto temos a atitude professoral, a qual pressupõe o uso legitimado de estratégias punitivas em relação aos alunos, como reprovações e castigos, que não se enquadram nos moldes sociais da instituição escolar. A mesma violência nega e visa inibir a possibilidade de que um jogador venha a assumir ou expressar publicamente afetividade ou identidade sexual que não condiga com o projeto de masculinidade heterossexual (Pinto, 2014).

Nessa ótica, a homofobia (velada ou explícita no discurso das instituições) também funciona como um dispositivo da sexualidade (Foucault, 1996), pois é o mecanismo que proíbe e controla a existência dos homossexuais em diversos espaços sociais e no esporte ao estipular verdades sobre quem pode ou não praticar tal atividade. Ela não só é uma forma de resistência contra a invasão da cultura gay no esporte, como funciona como elemento protetor da masculinidade hegemônica. Alguns técnicos de futebol sustentam que o atleta se mantenha "quieto" se quiser continuar jogando e políticas de grandes times proíbem os jogadores de falar sobre homossexualidade, com o argumento de não prejudicarem suas respectivas equipes (Almeida \& Soares, 2012). O preconceito contra homossexuais no futebol revela mais do que apenas o afastamento da subjetividade sexual indesejada, mas também concede a autoafirmação masculina, ordenada pela censura à prática homossexual (Moura, 2017).

Dessa maneira, podemos observar a presença da homonormatividade nesse contexto. Longe de ser um antagonismo ao conceito de heteronormatividade, a homonormatividade é uma vivência de gênero performatizada de forma que torne a homossexualidade "aceitável" aos olhos da norma, e isso se faz através de uma progressiva aproximação com os valores e moralidades cultivados pela heteronorma (Oliveira, 2013). O que explica por exemplo, o fato de que homossexuais devem ocultar sua identidade homossexual para permanecer no futebol, performatizando a masculinidade tipicamente heterossexual. 
Ao não performatizar o projeto da heterossexualidade nesse contexto, o atleta fica sujeito a violência homofóbica, que no futebol eclode como recusa à diferença. Ela não é pontual, inesperada e nem casual. São violências tramadas sobre uma lógica de não se perder a estabilidade heterossexual emaranhada no futebol em que a dominação masculina é a norma (Almeida \& Soares, 2012).

\section{A homossociabilidade no futebol}

Em contraste, o futebol é um "lócus por excelência da homossociabilidade", que admite demonstrações de afetividade entre homens que não costumam ser manifestadas no dia a dia. Kimmel (1998), explica que a sociabilidade entre homens é um fator crucial no desenvolvimento das masculinidades. Exemplos dessa homossociabilidade são os abraços intensos e calorosos na comemoração de gols do time pelo qual se torce. Porém a demonstração de afeto a outro homem, quando não se presta a render homenagem ao time que torce, é duramente repelida e hostilizada por não condizer com o projeto do homem heterossexual (Pinto, 2014).

A afetividade pelo clube, com claras demonstrações de "paixão" constitui para esses torcedores algo aceitável e que se estabelece como uma forma de performatividade masculina heterossexual, sendo que em momentos onde há um gol, por exemplo, a comemoração com abraços não constitui algo de homossexuais. Porém, essa demonstração só se aceita entre uma mesma torcida. Abraçar o torcedor do time adversário pode constituir uma prática homossexual na lógica das representações de masculinidades nos estádios de futebol (Silva, 2014).

\section{Os estádios, a torcida, a linguagem e a mídia}

Os estádios, por sua vez, não se constituem apenas da masculinidade, mas sim de diversas masculinidades, tendo em vista que fatores interseccionais como raça/etnia, classe social etc., inserem-se nessa construção identitária (Silva, 2014). Os torcedores enaltecerem a imagem de masculinidade, em detrimento de uma suposta falta de virilidade, passividade e feminização dos adversários. Tal forma de pensar e agir é comumente expressa nas manifestações coletivas, como nos cânticos insultuosos entoados pelos torcedores e jogadores (Pereira et al, 2014).
Os xingamentos e associações à homossexualidade e à feminilidade soam como ofensas para desqualificação do outro, conformando um cenário de rivalidades em que tais expressões são entendidas como parte da "cultura do jogo" (Pinto, 2014).

E nesse universo, cabe refletir sobre a articulação política da sociedade civil em discutir estes símbolos de masculinidade performatizados. Isto ocorre pela linguagem construída ali, que utiliza no vocabulário vasto xingamento acerca daquele que rompe com o projeto heterossexual (Almeida \& Soares, 2012). A linguagem é também um meio de demonstrar dominação e força e também funciona como um dispositivo da sexualidade (Foucault, 1996). Nesse sentido, é utilizada para relegitimar as relações de um poder já ordenadas pela norma heterossexual. Com isso, a expressão 'bicha' utilizada de forma livre em um espaço público, garante que o homossexual tenha sua participação limitada/censurada no futebol (Moura, 2017). O ato que constrói a "bicha" está num contexto específico, em que esse sujeito homossexual é mais inferior ainda se é o passivo, ou seja, se no imaginário desta masculinidade é dominado pelo outro (Silva, 2014).

A linguagem também funciona como forma de agressão através de xingamentos homofóbicos recorrentes na depreciação de figuras como jogadores/torcedores do time adversário, juiz (quando favorece a equipe adversária) ou de jogadores e torcedores da própria equipe, cuja má atuação ou conduta inapropriada, coloquem em risco a ideia de "integridade" do grupo estabelecido e o próprio padrão normatizador geralmente com o intuito de criar algum tipo de desqualificação e desequilíbrio emocional que o leve a erro (Moura, 2017; Pinto, 2014).

Para além da representatividade das torcidas organizadas, outros agentes inseridos no universo do futebol, contribuem para a reafirmação e a "naturalização" da ideia de dominação masculina heterossexual, como, por exemplo, a mídia especializada, mediadora das informações e dos saberes sobre o jogo a serem transmitidos para o público, muitas vezes, contribuindo para afixar estereótipos, como a de que gays e mulheres não gostam ou não se interessam por futebol (Pinto, 2014). 
O que se observa, então, é que o campo de futebol não se restringe apenas ao espaço concreto do jogo. O campo é um modelo de sociabilidade que cogita o masculino onde há representações diversas de relações de poder existentes. O estádio de futebol é reflexo da família, da escola, do trabalho, enfim, dos espaços de socialização ao qual o homem aparece como figura central na tarefa de ação (Moura, 2017).

\section{Torcidas queers e inclusão}

$\mathrm{Na}$ contramão do discurso daqueles que exercem e reafirmam a dominação masculina, há iniciativas como a dos grupos que criaram as torcidas queer e livres, ao elaborar práticas discursivas confrontando a hegemonia masculina da heteronormatividade. Mesmo com as muitas ameaças, hostilidades e constrangimentos que dificultam a transposição da esfera virtual para a apropriação de espaços nas arquibancadas dos estádios, essas torcidas têm suscitado reflexões e conseguido ampliar a visibilidade para o debate sobre a homofobia e o machismo como posturas que segregam e criam obstáculos ao reconhecimento de homossexuais no contexto do futebol. Reivindicam que essas pessoas tenham a sua participação e lugares legitimados nas práticas que dão sentido ao jogo futebol, entendendo ser esse um passo importante para a construção de uma sociedade brasileira igualitária, orientada pelo reconhecimento e o respeito às múltiplas subjetividades (Pinto, 2014).

A teoria queer que tem como uma das principais representantes a teórica Judith Butler (2003), questiona os pressupostos e saberes sobre os corpos, quebrando com a noção de uma essência masculina e feminina, comumente tida como verdade devido a heteronorma. O queer diz respeito a aquilo que é estranho, fala sobre o empoderamento dos corpos subalternos e marginais e faz esses corpos fortes ao abraçarem sua estranheza como forma de orgulho. E a partir disso, podemos observar uma possíveis mudanças na masculinidade tradicional, com a possibilidade da masculinidade inclusiva, que é a ideia de que múltiplas masculinidades podem coexistir sem qualquer arranjo hierárquico em culturas de homofobia decrescente e dentro desse arcabouço teórico, entende-se que várias formas de masculinidade retêm igual valor cultural, onde se rejeita da homofobia, o heterossexismo compulsório e o sexismo pois todas as masculinidades podem conviver juntas dentro do mesmo ambiente com igual valor cultural. Parte da influência na diminuição da homofobia cultural pode vir da mídia através da mudança na apresentação da homossexualidade (particularmente nos homens) (Cleland, 2014).

Embora o privilégio da heterossexualidade permaneça em múltiplas formas, ocorreram mudanças positivas para homens e mulheres gays desde a virada do século XXI. Um aspecto disso é o aumento da aceitação social da homossexualidade, em parte devido à maior visibilidade e retratos positivos de homens e mulheres gays nos meios de comunicação de massa (Cleland, 2014).

Desde 2013 apareceram na rede social Facebook comunidades que se apresentavam como torcidas queer e livres de alguns dos principais times do Brasil. Essas páginas divulgam conteúdos, próprios ou publicados na mídia, questionando a heteronormatividade, que privilegia um modelo de masculinidade como legítimo participante das práticas do futebol, e contrapondo-se à homofobia e ao machismo que segregam gays e mulheres dos estádios (Pinto, 2014).

Apesar da natureza mais inclusiva da masculinidade evidente no esporte e um pequeno número de esportistas masculinos assumindo sua identidade homossexual publicamente, a cultura heteronormativa de esportes de equipe de contato claramente forçou muitos homens gays a permanecerem no armário. No entanto, talvez o apelo metrossexual dos esportistas modernos (em particular, os jogadores de futebol) e as estruturas sociais cada vez mais fluidas possam auxiliar na inclusão de homossexuais no futebol sem que esses precisem esconder sua identidade sexual (Cleland, 2014).

\section{Algumas considerações}

A partir do exposto nessa discussão, pode-se perceber que o futebol não é um campo de acesso livre a todas as populações. A revisão sugeriu que o futebol é um campo de performatividade do projeto de masculinidade heterossexual e quem não se encaixa nesse projeto tende a ser marginalizado.

A homossociabilidade apareceu como uma forma de performatividade aceita dentro do contexto da paixão pelo time e a torcida acaba por utilizar a linguagem como um dispositivo regulador das expressões de sexualidade e gênero na prática do esporte. A homofobia presente expressa através da linguagem 
pode ser compreendida como uma forma de banir a homossexualidade desse contexto pois ela ameaça a estabilidade do projeto de homem heterossexual confirmado e reconfirmado no futebol.

De forma geral, percebeu-se que o futebol não é somente um esporte, as um campo de relações de poder e relações de masculinidades, mas mesmo em um cenário ainda hostil para homossexuais, as possibilidades de mudança nesse contexto são proeminentes. As percepções de masculinidades inclusivas apareceram na literatura como uma forma de promover a convivência segura entre héteros e homossexuais. A literatura também mostrou que as próprias torcidas LGBT's estão se organizando na busca do direito de vivenciarem a prática esportiva.

As mudanças na maneira como a cultura tem percebido a homossexualidade tem auxiliado na possibilidade de atletas gays fazerem parte do futebol, porém, ainda estamos em passos lentos e discretos. Para que a inclusão ocorra propriamente dito (e não somente um processo de interação social conveniente entre héteros e homossexuais) é preciso que avancemos nas desconstruções dos estereótipos de gênero que atravessam toda a sociedade.

Por fim, as limitações do estudo estão dadas a partir da própria metodologia adotada, que ao tempo que desvela uma questão tabu e estereótipos, demanda estudos mais aprofundados para análise mais robustas da questão, assim, espera-se que este trabalho possa despertar o interesse por futuras pesquisas sobre o objeto de pesquisa para que se possibilite a compreensão das experiências de masculinidades e sexualidades dissidentes no contexto do futebol. Ademais, ressalta-se a importância de se compreender não somente sobre a homossexualidade no contexto do esporte, (nesse caso especificadamente no futebol) mas também sobre a vivência de pessoas transexuais nesses contextos, visto que nenhum artigo selecionado tratou desse último público.

\section{Conflitos de interesses}

Nenhum conflito financeiro, legal ou político envolvendo terceiros (governo, empresas e fundações privadas, etc.) foi declarado para nenhum aspecto do trabalho submetido (incluindo, mas não se limitando a subvenções e financiamentos, participação em conselho consultivo, desenho de estudo, preparação de manuscrito, análise estatística, etc.).

\section{Referências}

Abrahao, B. O. L., \& Soares, A. J.G. (2012). O futebol na construção da identidade nacional: uma análise sobre os jogos "pretos x brancos". Revista Brasileira de Educação Física e Esporte, 26(1), 47-61. Recuperado de https://www.scielo. br/scielo.php?pid=S1807-55092012000100006\&script=sci_ abstract\&tIng=pt. doi: 10.1590/S1807-55092012000100006

Almeida, M. B., \& Soares, A. S. (2012). O futebol no banco dos réus: caso da homofobia. Movimento, 18(01), 301-321. Recuperado de https://seer.ufrgs.br/Movimento/article/ view/20826/17386

Bandeira, G. A. (2010). Um currículo de masculinidades nos estádios de futebol. Revista Brasileira de Educação, 15(44), 342-351. Recuperado de https://www.scielo.br/ scielo.php?pid=S1413-24782010000200010\&script=sci_ abstract\&tIng=pt. doi: $\underline{10.1590 / S 1413-24782010000200010}$

Bardin, L. (2011). Análise de conteúdo. São Paulo: Edições 70.

Bourdieu, P. (1989). O poder simbólico. Lisboa: Difel.

Butler, J. (2003). Problemas de gênero: feminismo e a subversão da identidade. Rio de Janeiro: Civilização Brasileira.

Caldas, W. (1986). O futebol no país do futebol. Lua Nova, 3(2), 24-30. Recuperado de https://www.scielo.br/scielo. php?script=sci_arttext\&pid=S0102-64451986000300005. doi: $\underline{10.1590 / S 0102-64451986000300005}$

Camargo, W. X. (2018). O armário da sexualidade no mundo esportivo. Revista Estudos Feministas, 26(1), e42816. Recuperado de http://www.scielo.br/pdf/ref/v26n1/1806 9584-ref-26-01-e42816.pdf. doi: 10.1590/1806$\underline{9584.2018 \mathrm{v} 26 \mathrm{n} 142816}$

Carvalho, H. P., Oliveira, F. R., Sampaio, T. M. V., Ferrari, E. P., \& Cardoso, F. L. (2017). Conflitos entre a orientação sexual e a orientação de gênero na identidade de atletas profissionais de voleibol: a percepção de atletas homossexuais. Revista Brasileira de Ciência e Movimento, 25(2), 84-98. Recuperado de https://portalrevistas.ucb.br/ index.php/RBCM/article/view/6565/pdf. doi: $10.18511 /$ rbcm.v25i2.6565

Castro, M. G., Abramovay, M., \& Silva, L. B. (2004). Juventude e sexualidade. Brasília: UNESCO Brasil. Recuperado de https://pt.slideshare.net/bibliotecasaude/2722-Ijuventude-e-sexualidade

Cleland, J. (2014). Association Football and the Representation of Homosexuality by the Print Media: A Case Study of Anton Hysén. Journal of Homosexuality, 61(9), 1269-1287. Recuperado de https://www.tandfonline. com/doi/abs/10.1080/00918369.2014.926765. doi: $\underline{10.1080 / 00918369.2014 .926765}$ 
Connell, R.W., \& Messerschmidt, J. W. (2013). Masculinidade hegemônica: repensando o conceito. Revista Estudos Feminitas, 21(1), 241-282. Recuperado de https://www. scielo.br/scielo.php?script=sci_arttext\&pid=\$0104026X2013000100014. doi: 10.1590/S0104026X2013000100014

Connell, R.W. (1995). Masculinities. Berkeley: University of California Press.

Costa, Â. B., \& Nardi, H. C. (2015). Homofobia e preconceito contra diversidade sexual: debate conceitual. Temas em Psicologia, 23(3), 715-726. Recuperado de http://pepsic. bvsalud.org/scielo.php?script=sci_arttext\&pid=\$1413389X2015000300015. doi: 10.9788/TP2015.3-15

Cordeiro, A. M., Oliveira, G. M., Rentería, J. M., \& Guimarães, C. A. (2007). Revisão sistemática: uma revisão narrativa. Revista do Colégio Brasileiro de Cirurgiões, 34(6), 428431. Recuperado de https://www.scielo.br/scielo. php?script=sci_arttext\&pid=S0100-69912007000600012. doi: $10.1590 /$ S0100-69912007000600012

Evans, D., \& Pearson, A. (2001). Systematic reviews: gatekeepers of nursing knowledge. Journal of Clinical Nursing, 10(5), 593-599. Recuperado de https://pubmed.ncbi.nlm.nih. gov/11822509/. doi: 10.1046/j.1365-2702.2001.00517.x

Foucault, M. (1996). Microfísica do poder. Rio de Janeiro: Graal.

Gomes, R. (2008). Sexualidade masculina, gênero e saúde. Rio de Janeiro: Fiocruz.

Kimmel, M. S. (1998). A produção simultânea de masculinidades hegemônicas e subalternas. Horizontes Antropológicos, 4(9), 103-117. Recuperado de https://www.scielo. br/scielo.php?script=sci_abstract\&pid=S010471831998000200103\&lng=pt\&nrm=iso. doi: $10.1590 /$ S0104-71831998000200007

Leoncini, M. P., \& Silva, M. T. (2005). Entendendo o futebol como um negócio: um estudo exploratório. Gestão \& Produção, 12(1), 11-23. Recuperado de https://www.scielo.br/scielo. php?script=sci_abstract $\&$ pid $=$ S0104-530X200500010 0003\&lng=en\&nrm=iso\&tlng=pt. doi: 10.1590/S0104$\underline{530 \times 2005000100003}$

Louro, G. L. (2000). O corpo educado: pedagogias da sexualidade. (3a ed.). Belo Horizonte: Autêntica.

Martins, S. R. C. (2015). Uniões homoafetivas: da invisibilidade à entidade familiar. (Dissertação de Mestrado). Faculdade de Direito, Universidade de São Paulo, São Paulo, SP, Brasil. Recuperado de https://www.teses.usp.br/teses/ disponiveis/2/2131/tde-06092016-160012/publico/Versao_ Simplificada_SandraReginaCarvalhoMartins.pdf
Menezes, A. B. C., \& Brito, R. C. S. (2007). Reflexão sobre a homossexualidade como subproduto da evolução do prazer. Psicologia em Estudo, 12(1), 133-139. Recuperado de https://www.scielo.br/scielo.php?pid=S1413$73722007000100016 \&$ script=sci_abstract\&tlng=pt. doi: 10.1590/S1413-73722007000100016

Moura, J. C. C. (2017). O direito em fala: sobre bichas e homens no futebol brasileiro. Revista Espaço Acadêmico, 17(198), 70-79. Recuperado de http://periodicos.uem.br/ojs/index. php/EspacoAcademico/article/view/37993

Natarelli, T. R. P., Braga, I. F., Oliveira, W. A., \& Silva, M. A. I. (2015). O impacto da homofobia na saúde do adolescente. Escola Anna Nery, 19(4), 664-670. Recuperado de https://www.scielo.br/scielo.php?script=sci_ arttext\&pid=S1414-81452015000400664. doi: $10.5935 / 1414-8145.20150089$

Oliveira, J. M. (2013). Cidadania sexual sob suspeita: uma meditação sobre as fundações homonormativas e neo-liberais de uma cidadania de "consolação". Psicologia \& Sociedade, 25(1), 68-78. Recuperado de https://www.scielo.br/scielo.php?pid=S0102$71822013000100009 \&$ script=sci_abstract\&tlng=pt. doi: 10.1590/S0102-71822013000100009

Pereira, A. S. L. S., Alfaia, A. J. B., Souza, L. E. C., \& Lima, T. J. S. (2014). Preconceito contra homossexuais no contexto do futebol. Psicologia \& Sociedade, 26(3), 737-745. Recuperado de https://www.scielo.br/scielo.php?pid=S0102$71822014000300022 \&$ script=sci_abstract\&tlng=pt. doi: 10.1590/S0102-71822014000300022

Pinto, M. R. (2014). Torcidas Queer e Livres em Campo: Sexualidade e Novas Práticas Discursivas no Futebol. Ponto Urbe: Revista do núcleo de antropologia urbana da USP 14, 1-11. Recuperado de https://journals.openedition. org/pontourbe/1460. doi: 10.4000/pontourbe.1460

Rubin, G. (2003). Pensando sobre sexo: notas para uma teoria radical da política da sexualidade. Brasil: Mimeo

Secretaria Especial de Direitos Humanos (2016). Relatório de Violência Homofóbica no Brasil: ano 2013. Brasília: Ministério das Mulheres, da Igualdade Racial e dos Direitos Humanos. Recuperado de http://www.direito.mppr.mp.br/arquivos/File/ RelatorioViolenciaHomofobicaBR2013.pdf

Silva, K. E. P. (2014). Da coligay ao sheik - (re)produção da homossexualidade no espaço de masculinidades: uma análise de discursos no campo futebolístico. Oficina do Historiador - EDIPUCRS, (Suplemento especial), 1956-1970. Recuperado de http://revistaseletronicas.pucrs.br/ojs/ index.php/oficinadohistoriador/article/view/19051/12110 